\title{
Some Physiochemical and Microbiological Characteristics of Wastewater and Possibility Usage in Agriculture
}

\author{
Nagwa S. A. Alraaydi ${ }^{1}$, Saleh H. M. El-majberi ${ }^{1}$, Hatem H. M. Alfakhri ${ }^{2}$ \& Twefeig Elbagermi $^{3}$ \\ ${ }^{I}$ Dept. of Botany, Faculty of Science, Benghazi University, Libya. ${ }^{2}$ Dept. of Environmental Sciences and Engineering, Libyan \\ Academy of Benghazi, Libya. ${ }^{3}$ Dept. of Environmental Health, Faculty of Public Health, Benghazi University, Libya.
}

Copyright: () 2021 Nagwa S.A. Alraaydi et al. This is an open access article distributed under the terms of the Creative Commons Attribution License, which permits unrestricted use, distribution, and reproduction in any medium, provided the original author and source are credited.

\section{ABSTRACT}

This study focuses on treating wastewater with natural materials (Charcoal and lime), identifying the physiochemical properties, identifying microorganisms in treated and untreated wastewater, and the possibility of using treated wastewater in agriculture by studying two different types of wastewater collected from two areas in Benghazi (Al-Kish and Sarti sites) in order to find out their suitability for agriculture and some other uses. The Microbiological analysis results were as follows; the growth of bacterial colonies represented in Kleibseilla pnewmonia in wastewater collected from the Sirty sites and Pseudomonas aeuroginosa \& Escherichia coli from wastewater collected from the El-Kish sites, where a biological analysis of the wastewater after treating by using two types of economic and available materials in nature Calcium carbonate "lime" and Charcoal after replanting the treated wastewater with the same previous method, we obtained bacterial growth, Pseudomonas aeuroginosa in wastewater treatment by Calcium carbonate "Lime" and Escherichia coli growth in wastewater treatment by Charcoal. Wastewater treatment by Calcium carbonate "Lime" and Charcoal did not show any microbial growth, this study was illustrated there was not growth from any kind of fungi from the studied wastewater treatment and un-treatment.

Wastewater treatment was found that it is possible to benefit from the treated wastewater to irrigate green areas and insensitive crops without soil degradation, and criteria for assessing the suitability of water for irrigation according to the United States Salinity Laboratory (USSL) wastewater treatment samples are located in class C3-S1, it cannot be used to irrigate sensitive crops, especially citrus fruits, and it should only be used in lands that do not have impervious layers that prevent leaching because they need washing.

Keywords: Wastewater, Treatment, Lime, Charcoal.

\section{Introduction}

Water is the most important component of life on the planet, and one of the most important factors of its continuation in appearance and in the interior, and plays an advanced role in the formation and development of soils, and determines the level of different forms of biogeochemical activity in them, and because all neighborhoods made water and a large proportion of between 70 and $97 \%$ weight. Water has gained great importance, making it the first determinant of agricultural production (Sonune and Ghate, 2004). Most of the Arab region is characterized by a dry and semi-arid climate. Therefore, most Arab countries suffer from water budget deficits due to increasing water needs resulting from increasing population, growing economic and social development requirements, limited opportunities for development of traditional water resources and deterioration of their quantity and quality due to pressure on water resources limited. Excretion of huge and increasing quantities of wastewater result in polluting the environment and fresh water sources. Both causes adversely affect the situation unless remedied. The solution to remedy this is to collect, treat and reuse them: Add new water resources available to reduce water deficit and Safe disposal of wastewater contaminated with water, soil, air and natural resources (Kirby, 2016). Wastewater treatment and reuse is not new, and knowledge on this topic has evolved and advanced throughout human history. Reuse of untreated municipal wastewater has been practiced for many centuries with the objective of diverting human waste outside of urban settlements. Likewise, land application of domestic wastewater is an old and common practice, which has gone through different stages of development. This 
has led to better understanding of process and treatment technology and the eventual development of water quality standards (Paranychianakis, et al., 2015).

\subsection{Challenges on wastewater treatment and reuse}

Water reuse has been dubbed the "greatest challenge of the next century" as water supplies remain the same and water demands increase because of increasing populations. Use of municipal wastewater (sewage effluent) ranges from non-potable purposes such as agricultural and urban irrigation, power plant cooling and other industrial purposes, and environmental uses (wetlands, wildlife refuges, riparian habitats), to potable uses.

Treated wastewater is a new source that can be used to irrigate agricultural crops and domestic uses, especially in areas with water scarcity. A range of social, religious, cultural and economic factors play a role in population decisions to accept the use of treated wastewater for irrigation of crops, which is related to environmental awareness and the population's understanding of the use of treated water (Terkawi, 2016).

\subsection{The reality of wastewater in Libya}

The urban growth processes in the Libyan regions during the past five decades were accompanied by the establishment of a large number of systems for collecting and treating urban wastewater for the purpose of protecting public health and the environment and reusing treated water to be a sustainable and replaceable water source. The techniques of urban wastewater treatment and the performance levels of these systems varied widely Significant, but it all led to the decline and stop completely after a short period of operation.

The number of wastewater treatment plants that were established in Libya during the period 1960-1985 of the last century amounts to more than (85) large and small stations. Most of these stations operate with a long-ventilated activated sludge system and a few with oxidation ponds, and a very limited number operates with a biological filter system (Green Hill Station first phase In Tripoli and the Qawarsha station in Benghazi today, and Sebha and Tobruk previously) (Al-Zu'bi, et. al., 2014).

\subsection{Objectives}

The major objectives of the research are outlined below:

1-Bioanalysis of sewage water to detect the quantity and quality of microorganisms (Fungi or Bacteria).

2-Investigation some Physical and chemical characters of sewage water in the study area.

3-To insight into appropriate technology for treatments sewage water.

4-Testing the treated and untreated sewage water in agriculture.

\section{Material and Methods}

\subsection{Location of study}

Benghazi city was selected as study research area, in order to high population density, reacted with over use of tap water for drinking, washing and cleaning. More than $50 \%$ of fresh water were drainage to sewage pipes and discharged in the sea. Over flooding of sewage water sometimes occur specially during winter months. 


\subsection{Water sampling}

Wastewater samples were collected randomly from two sites in Benghazi city (Al serty and Alkeish area) 50 liters were taken from raw wastewater resources and from storage basin. Samples were marked and kept in room temperature $\left(25 \pm 2^{\circ} \mathrm{C}\right)$ (Fig.1).
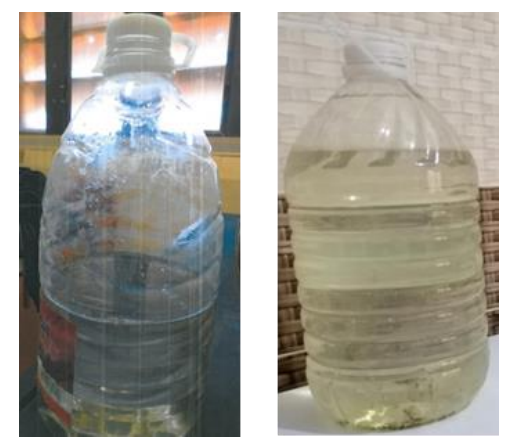

Fig.1. Sample of wastewater

\subsection{Microbiological Analysis}

\subsubsection{Isolation of microorganism from collected wastewater samples}

Firstly, $5 \mathrm{~mm}$ of raw wastewater was taken and placed on the selected artificial media. Two selective media Eosin Methylene Blue Agar (EMB) and Nutrient Agar (used only for cultivation raw wastewater from Alserty area). Eosin Methylene Blue Agar was used for the cultivation of the treated raw wastewater testing. Note: the samples collected from Alserty area just underwent to first cultivation only because it runs out from it was source, then the cultivation process was carried out under aseptic conditions by cultivating two dishes from the raw wastewater samples collected from Alkeish and Alserty, 1 dish for each collect from these raw wastewater. Cultivated dishes were incubated at $38^{\circ} \mathrm{C}$ temperature for 3-5 Days until appearance of microbes growth and the formation of colonies, whether fungal or bacterial growth. Re isolation method have been done to separate growing fungi from bacterial colonies if it is present. Identification of fungi has been done based on morphological characters (Tsacev, 2001). While the identification of bacteria by morphological character of growing colony and using phonex ${ }^{\mathrm{TM}}$ system.

\subsubsection{Re-cultivation of treatment wastewater}

This was done by using the Eosin Methylene Blue Agar. The cultivation applying with the same way in the identification of growing microbes (Fig.2).
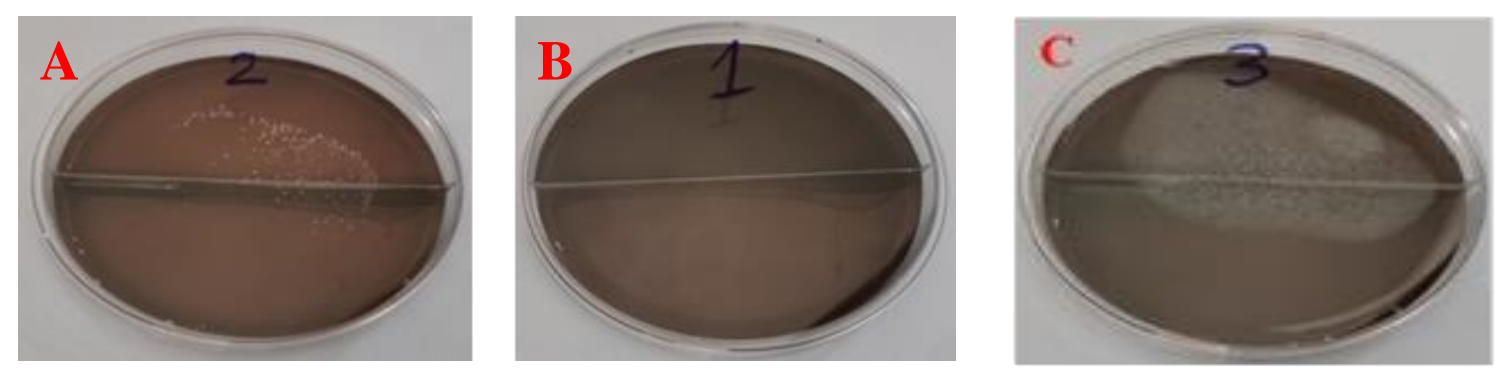

Fig.2. Isolates of treatment wastewater 

A: Wastewater treatment by using Charcoal.
B: Wastewater treatment by using Calcium Carbonate.
C: Wastewater treatment by using Calcium Carbonate and Charcoal.

\subsection{Natural Materials Treatment}

\subsubsection{Charcoal treatment}

One kilogram (1 kg) from fragmentation and grinding charcoal was prepared, was carried out and placed in a sterile plastic container, then the wastewater sample was filtered using filtration device and filter paper to remove the suspended solids, then the charcoal was submerged with raw wastewater, the treatment process was done for wastewater for a period of 7-8 days, in each day the sample of treated wastewater is filtered with filtration device and filter paper and replaced amount of charcoal that previously used with new another quantity (Fig.3).
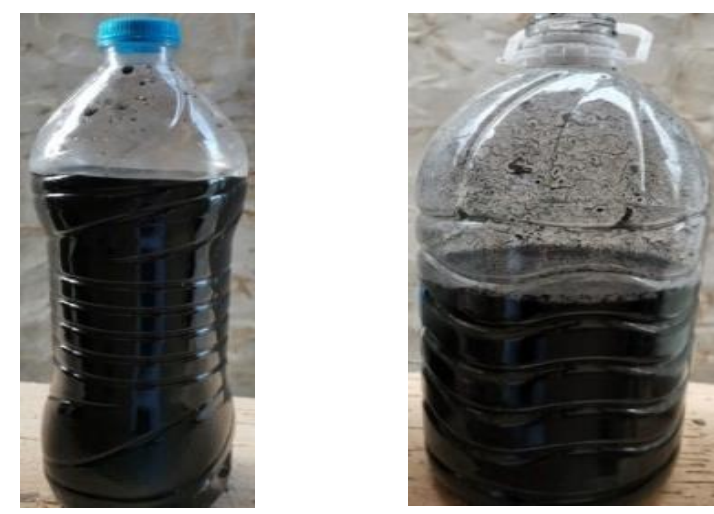

Fig.3. Sample of treated wastewater with using

\subsubsection{Lime (Calcium Carbonate) treatment}

Charcoal

One kilogram (1 kg) from fragmentation and grinding of lime (Calcium Carbonate) was prepared, it was carried out and placed in a sterile plastic container, then the wastewater sample was filtered using filtration device and filter paper to remove suspended solids, then the lime (calcium carbonate) was immersed in raw wastewater, the treatment process was carried out for a period of time 7-8 days, every day the treated sewage sample is filtered using filtration device and filter paper and replaced the amount of lime (Calcium Carbonate) that previously used with new another quantity (Fig.4).
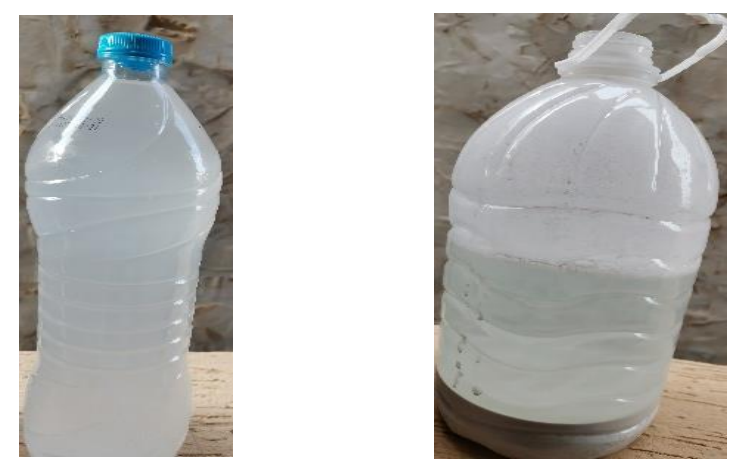

Fig.4. Sample of treated wastewater with using Lime 


\subsubsection{Lime and Charcoal treatment}

Half a kilogram $(1 / 2 \mathrm{~kg})$ of charcoal was mixed with half a kilogram $(1 / 2 \mathrm{~kg})$ of lime (calcium carbonate) and this mixture of materials was immersed in raw waste water and the treatment was carried out for a period of 7-8 days, every day the treated raw wastewater sample was filtered using filtration device and filter paper and replaced the amount of lime (Calcium Carbonate and Charcoal) that previously used (Fig.5).
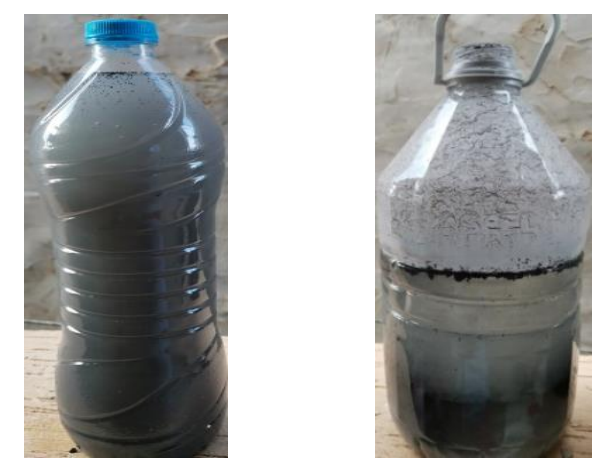

Fig.5. Sample of treated wastewater with using Lime and Charcoal

\subsection{Assessment of Physical and Chemical properties of wastewater before and after treatments}

The experiments were conducted at Benghazi city. In this study, we discussed the physical and chemical properties of wastewater in the city of Benghazi, and we will focus mainly on presenting the results of measurements for the following pollutants:

- $\mathrm{T}$ (Temperature $\left.{ }^{\circ} \mathrm{C}\right)$.

- $\mathrm{pH}$ (Measured by a pH meter).

- EC (Electrical Conductivity measured by an EC meter, expressed in $\mu \mathrm{m} / \mathrm{cm}$ ).

- TDS (Total Dissolved Solids mg/l).

- $\mathrm{NO}_{3}$ "Nitrate" (estimated by Spectrophotometer at the positive length of 220 nanometers).

- $\mathrm{HCO}_{3}$.

- $\mathrm{CO}_{3}$ (Carbonate $\left(\mathrm{CO}_{3}\right)$ and bicarbonate $\left(\mathrm{HCO}_{3}\right)$ was appreciated by calibration against acid chloride titer 0.02).

- Total Alkalinity.

- $\mathrm{Cl}$ (Chloride) Dissolved anions: $\mathrm{Cl}$, which was valued by titration against silver nitrate $\mathrm{Ag}\left(\mathrm{No}_{3}\right)_{2} \& 0.02$ titer.

- $\mathrm{Na}$ (Sodium).

- K (Potassium), Sodium (Na) was determined by a spectrophotometer.

- $\mathrm{SO} 4$ (Sulfate) $\left(\mathrm{SO}_{4}\right)$ was estimated by the difference between the total cations and anions $\mathrm{SO}_{4}=(\mathrm{Na}+\mathrm{Ca}+\mathrm{Mg}+\mathrm{k})$.

$-\left(\mathrm{CO}_{3}+\mathrm{HCO}_{3}+\mathrm{Cl}\right)$.

- $\mathrm{Mg}^{++}$(Magnesium Ion) \& Magnesium Hardness. 
- $\mathrm{Ca}^{++}$(Calcium Ion) \& Calcium Hardness. Calcium (Ca) and magnesium (Mg) was appreciated against the titration solution of EDTA "Ethylene diamine tetra acetic acid" titer 0.01 .

- Total Hardness

- Sodium Absorption Ratio (SAR). SAR= Na/((Ca+Mg)/2 $)^{\wedge} 2$.

- Estimate Residual Sodium Carbonate (RSC).

- The filtered water using a filtering device and removal of air (VACCUIM) and cellulose filter paper.

\subsection{Germination Bioassay}

\subsubsection{Seed selection and examination}

Six species were selected after examining their safety, quality and freedom from diseases free and insects, three types of seeds of the Fabaceae family (Vicia faba, Cicer arietinun and Phaseolus vulgaris) were chosen and also three types from Poaceae family (Triticum aestivum, Hordeum vulgare and Zea mays).

\subsubsection{The effect of using irrigation with untreated and treated wastewater on planting the selected seeds in the} laboratory

We will discuss the effect of irrigation with untreated and treated raw wastewater on the cultivation of selected seeds on petri dishes and in the soil pots in the laboratory and compare the beginning of germination and the nature of the behavior of the irrigated seed types.

\subsubsection{Germination seeds on petri dishes}

We have conducted research experiments on the six species of seeds (Vicia faba, Cicer arietinun, Phaseolus vulgaris, Triticum aestivum, Hordeum vulgare and Zea mays) selected by planting them in Petri dishes containing a piece of sterile medical cotton and we put a number of seeds in each plate directly on the cotton and irrigated with raw wastewater. In addition, to other dishes that were irrigated them with wastewater that was treated by natural materials which mention previously, then placed these dishes at room temperature $(20-25)^{\circ} \mathrm{C}$. The irrigation with raw and treat wastewater was repeated every two days and must underwent to observation and recorded the beginning of the date of germination and the nature of the behavior of the seed types (Fig.6).

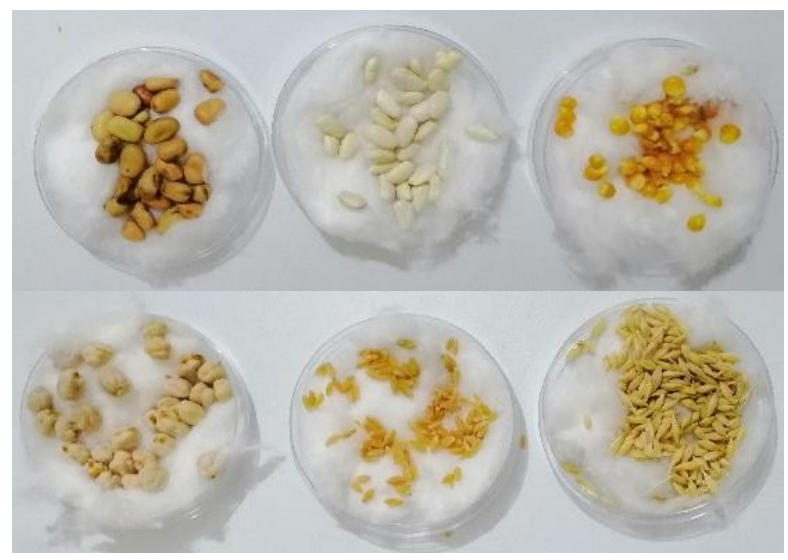

Fig.6. Germination seeds on petri dishes 


\subsubsection{Seedling growth bioassay}

Plastic pots were prepared and filled with soil and then prepared the selected 6 seeds (Beans, Chickpeas, Corn, broad bean, Barley and Wheat) were washed and sterilized by using a dilute chlorex solution with water and soaked for a minute and immediately washed with sterile distilled water and planted in the soil and irrigated it with treated wastewater, in addition to other seeds that were irrigated with raw wastewater, the plastic pots were kept at room temperature $(20-25)^{\circ} \mathrm{C}$, and the germination history and growth nature of each seed type were noted and recorded separately. The irrigation process with raw and treated wastewater was repeated every 2 days (Figs. 7-8).

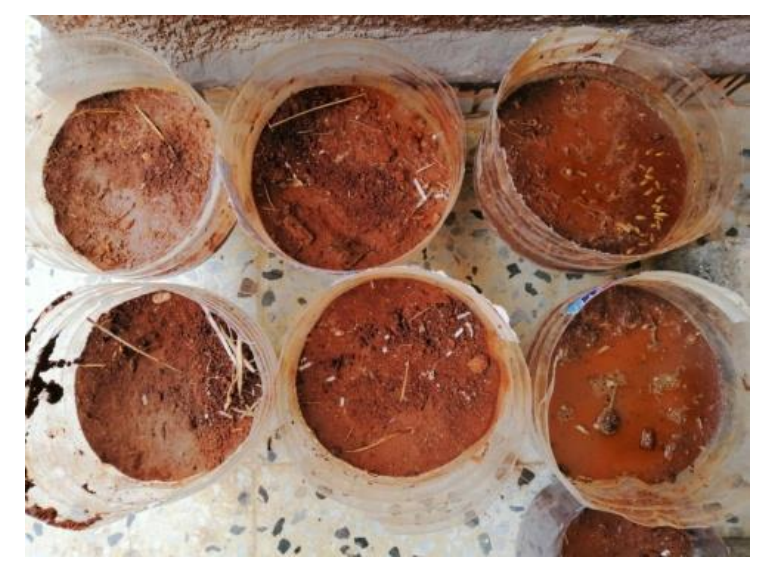

Fig.7. Germinated seeds in the soil irrigation by treated wastewater

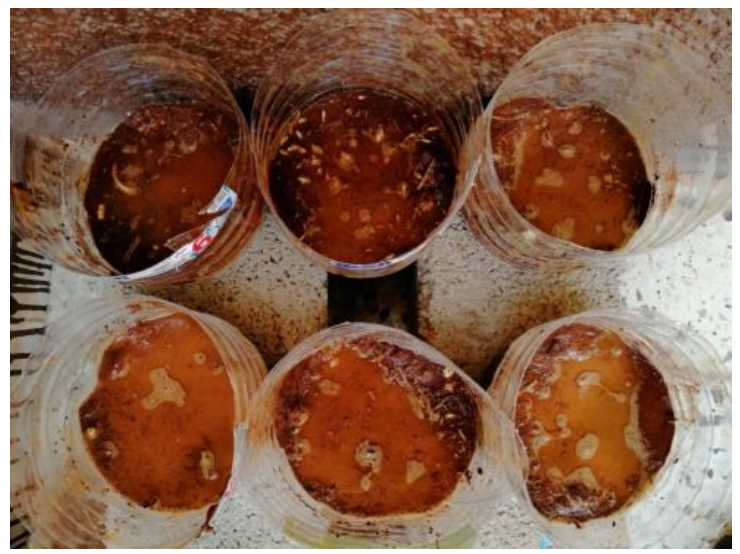

Fig.8. Germinated seeds in the soil irrigation by raw wastewater

\section{Result}

\subsection{Result of growing microorganisms (Fungi or Bacteria)}

One from selected raw wastewater studied from Alserty area it was disappear from this source so, just underwent to first cultivation to detect growing microorganism. After the process of cultivation raw wastewater collected from Alserty and Alkeish areas on the selected media ( on Nutrient Agar and Eosin Methylene Blue Agar "EMB") respectively, and incubated for 24 hours at $38^{\circ} \mathrm{C}$ had showed only bacterial growth which it identified by using microscopic examination and morphological characters of growing colonies. It was Klebsiella pneumonia at the first plate (Raw wastewater from Alserty area on Nutrient Agar). The description for this type of bacteria colony are small to moderate in size, convex, limy texture, white to yellow colour, smooth in edge, had bad smell and 
secrete yellow pigment, and their characteristic as gram negative, non-motile, short and thick and rods in shape. The second plate (Raw wastewater from Alkeish area on EMB Agar) was Pseudomonas aeruginosa and Escherichia coli. The characteristic of Pseudomonas aeruginosa as gram negative, rod shaped, motile ( polar flagella ), produce water soluble pigment which dissolve through the media, their colony was small, rough, flat edges and greenish .

While the characteristic of Escherichia coli as gram negative, rod shaped, non-spore forming, motile with peritrichous flagella or non-motile, their colony was slightly raised, entire margin, circular, smooth, low convex, grayish, white and opaque. After treated wastewater studied from Alkeish area and repeat the cultivation process on EMB Agar, the results of growing microbes as following, the third plate, was wastewater treated by using charcoal was Escherichia coli. And the fourth plate, wastewater treated by using calcium carbonate was Pseudomonas aeruginosa. And the fifth plate, wastewater treated by using both calcium carbonate and charcoal did not have any growth from microbes. This study was illustrated there that not growth from any kind of fungi from the studied wastewater (Fig.9).
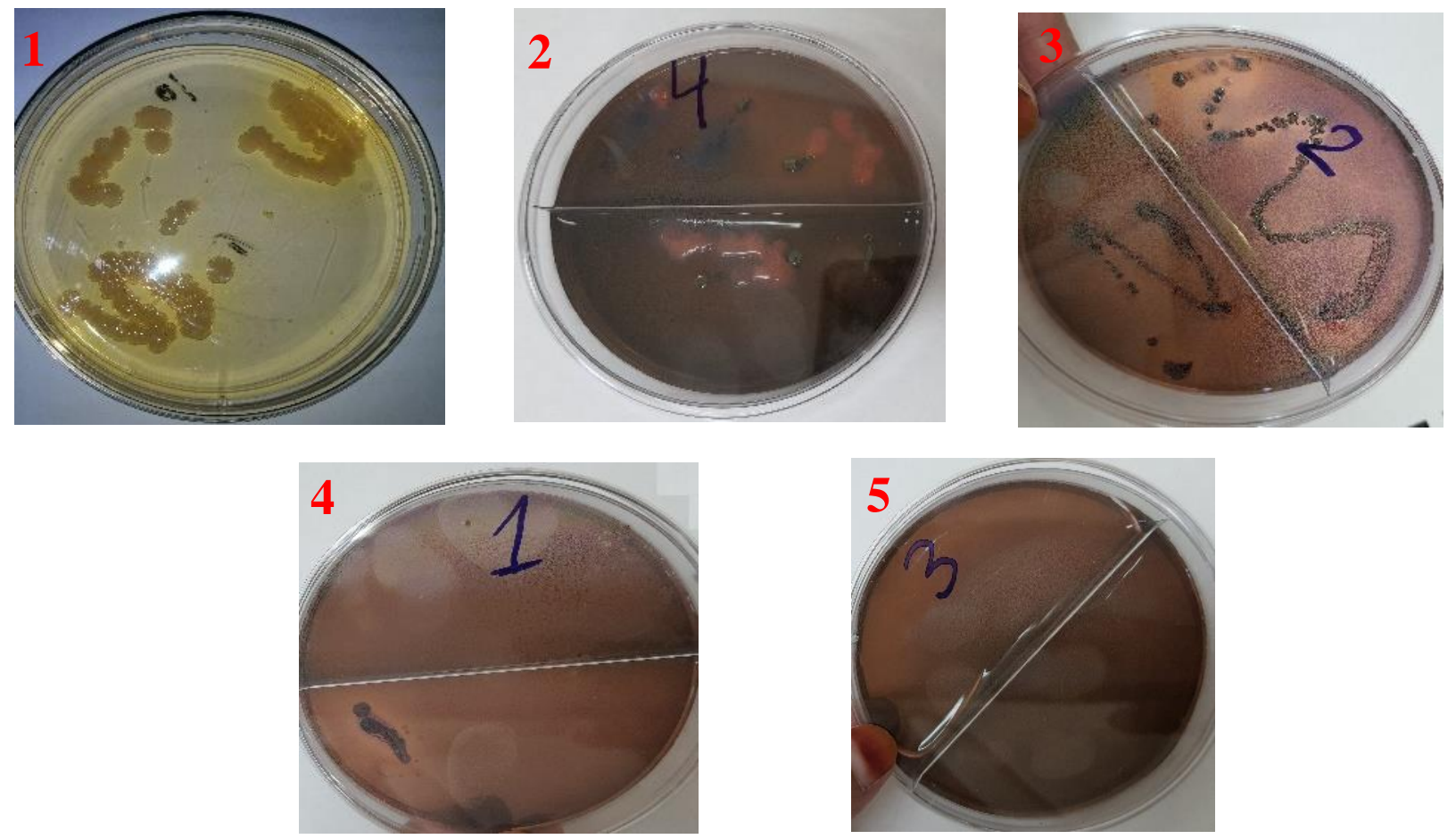

Fig.9. The Growth of Bacteria on Petri Dishes

1: First Dish Growth of Klebsiella pneumonia (Raw wastewater from Alserty area on Nutrient Agar).

2: Second Dish Growth of Pseudomonas aeruginosa and Escherichia coli (Raw wastewater from Alkeish area on EMB Agar).

3: Third Dish Growth of Escherichia coli (wastewater treatment by using charcoal on EMB Agar).

4: Forth Dish Growth of Pseudomonas aeruginosa (wastewater treatment by calcium carbonate on EMB Agar).

5: Fifth Dish no any growth (wastewater treatment by Calcium carbonate and Charcoal together on EMB Agar). 


\subsection{Result analyzed of raw wastewater}

The wastewater was analyzed chemically before being treated with the natural materials selected in this research, the results were mentioned below in the following:

Table 1. Result chemical analyses of raw wastewater

\begin{tabular}{|c|c|c|c|c|c|c|}
\hline No & $\mathbf{1}$ & $\mathbf{2}$ & $\mathbf{3}$ & $\mathbf{S D}$ & $\mathbf{R S D}$ & AVE \\
\hline $\mathbf{T}$ & 20.6 & 20.6 & 20.7 & 0.06 & 0.28 & 20.63 \\
\hline $\mathbf{p H}$ & 7.6 & 7.8 & 7.8 & 0.12 & 1.49 & 7.73 \\
\hline $\mathbf{E C}$ & 12400 & 11900 & 12200 & 251.66 & 2.07 & 12166.67 \\
\hline TDS & 8060 & 7735 & 7930 & 163.58 & 2.07 & 7908.33 \\
\hline NO3 & 19.9 & 20.4 & 21.1 & 0.60 & 2.95 & 20.47 \\
\hline Mg++ & 12.36 & 8.66 & 17.29 & 4.33 & 33.90 & 12.77 \\
\hline Ca++ & 25.624 & 28.824 & 19.216 & 4.89 & 19.92 & 24.55 \\
\hline HCO3 & 60.06 & 52.05 & 520.5 & 268.18 & 127.18 & 210.87 \\
\hline CO3 & 0 & 0 & 0 & 0.00 & 0.00 & 0.00 \\
\hline Cl & 144 & 132 & 128 & 8.33 & 6.18 & 134.67 \\
\hline Na & 496.1 & 496.2 & 503.8 & 4.42 & 0.89 & 498.70 \\
\hline K & 17.14 & 14.17 & 14.17 & 1.71 & 11.31 & 15.16 \\
\hline SO4 & 43.96 & 46.85 & 51.25 & 3.67 & 7.75 & 47.35 \\
\hline
\end{tabular}

* $\mathrm{SD}=$ Standard Deviation $\quad * \mathrm{RSD}=$ Relative Standard Deviation $\quad *$ AVE $=$ Average

\subsection{Result of analyzed treated wastewater by using natural materials}

Because the amount of raw sewage that is disposed of untreated in the sea and rivers and not taken advantage of properly, we have carried out a treatment process for raw sewage flowing from homes and human uses with inexpensive natural materials present in nature, the selection of charcoal and lime (calcium carbonate) powder in treating sewage water directly after collection and by simple and easy natural methods that can be made at the individual or country level for use in agriculture and some other uses.

\subsection{Result of analyzed wastewater treatment by using Charcoal}

After treating raw wastewater with charcoal must examined microscopically, and the results showed a significant decrease in the number of microorganisms, and this indicates that the molecules of these compounds absorb and 
adhere to the microorganism cells, which led to their death after a period of time due to the lack of nutrients and the effect of the chemical medium. As for the more acidic or alkaline, the sewage consists of $99 \%$ water and the remaining $1 \%$ dissolved organic and inorganic materials. When conducting the necessary analyzes, the following specifications are revealed when analyzing the water sample, as shown in following:

Table 2. Result treatment analyses of wastewater by using Charcoal

\begin{tabular}{|c|c|c|c|c|c|c|}
\hline No & $\mathbf{1}$ & $\mathbf{2}$ & $\mathbf{3}$ & $\mathbf{S D}$ & $\mathbf{R S D}$ & AVE \\
\hline $\mathbf{T}$ & 20.5 & 20.6 & 20.6 & 0.06 & 0.28 & 20.57 \\
\hline $\mathbf{p H}$ & 7.8 & 7.4 & 7.7 & 0.21 & 2.73 & 7.63 \\
\hline $\mathbf{E C}$ & 1570 & 1600 & 1630 & 30.00 & 1.88 & 1600 \\
\hline TDS & 1020.5 & 1040 & 1059.5 & 19.50 & 1.88 & 1040.00 \\
\hline NO3 & 64.8 & 63.9 & 64.6 & 0.47 & 0.73 & 64.43 \\
\hline Mg++ & 19.28 & 21.12 & 21.96 & 1.37 & 6.59 & 20.79 \\
\hline Ca++ & 32.028 & 22.42 & 27.48 & 4.81 & 17.60 & 27.31 \\
\hline HCO3 & 112.11 & 88.09 & 92.09 & 12.87 & 13.21 & 97.43 \\
\hline CO3 & 0 & 0 & 0 & 0.00 & 0.00 & 0.00 \\
\hline Cl & 272 & 240 & 204 & 34.02 & 14.25 & 238.67 \\
\hline Na & 1091 & 1091 & 1091 & 0.00 & 0.00 & 1091.00 \\
\hline K & 612.1 & 612.8 & 612.1 & 0.40 & 0.07 & 612.33 \\
\hline SO4 & 704.58 & 699.5 & 707 & 3.83 & 0.54 & 703.69 \\
\hline
\end{tabular}

\subsection{Result of treatment analyses of wastewater by using Lime (Calcium Carbonate)}

After treating raw wastewater using limestone, the results indicated that the microorganisms were lower than they were in raw wastewater and then analyzing this sample of treated wastewater by limestone. The following specifications are shown in the following:

Table 3. Result analyses of treatment wastewater with using Lime (Calcium Carbonate)

\begin{tabular}{|c|c|c|c|c|c|c|}
\hline No & $\mathbf{1}$ & $\mathbf{2}$ & $\mathbf{3}$ & $\mathbf{S D}$ & $\mathbf{R S D}$ & $\mathbf{A V E}$ \\
\hline $\mathbf{T}$ & 20.5 & 20.4 & 20.5 & 0.06 & 0.28 & 20.47 \\
\hline $\mathbf{p H}$ & 11.4 & 11.5 & 11.5 & 0.06 & 0.50 & 11.47 \\
\hline $\mathbf{E C}$ & 1260 & 1300 & 1350 & 45.09 & 3.46 & 1303.33 \\
\hline
\end{tabular}


Mediterranean Journal of Basic and Applied Sciences (MJBAS) Volume 5, Issue 4, Pages 27-43, Oct-Dec 2021

\begin{tabular}{|c|c|c|c|c|c|c|}
\hline TDS & 819 & 845 & 877.5 & 29.31 & 3.46 & 847.17 \\
\hline NO3 & 60.9 & 61.5 & 63.7 & 1.47 & 2.38 & 62.03 \\
\hline Mg++ & 8.25 & 4.22 & 6.11 & 2.02 & 32.56 & 6.19 \\
\hline Ca++ & 166.548 & 172.96 & 166.548 & 3.70 & 2.19 & 168.69 \\
\hline HCO3 & 229.83 & 231.5 & 227.9 & 1.80 & 0.78 & 229.74 \\
\hline CO3 & 36.84 & 39.08 & 36.7 & 1.34 & 3.56 & 37.54 \\
\hline Cl & 332 & 240 & 320 & 50.01 & 16.82 & 297.33 \\
\hline Na & 609 & 609 & 609.5 & 0.29 & 0.05 & 609.17 \\
\hline K & 34.29 & 34.31 & 34.29 & 0.01 & 0.03 & 34.30 \\
\hline SO4 & 21.65 & 24.68 & 28.55 & 3.46 & 13.86 & 24.96 \\
\hline
\end{tabular}

\subsection{Result of analyses treatment wastewater by using Lime and Charcoal}

After treating raw wastewater using limestone and charcoal together, and when performing analyzes of the treated wastewater sample, results after examination indicated a significant decrease in the number of microorganisms, and then analyzing this wastewater sample. The following specifications were shown in the following:

Table 4. Result analyses of treatment wastewater by using Lime and Charcoal

\begin{tabular}{|c|c|c|c|c|c|c|}
\hline No & $\mathbf{1}$ & $\mathbf{2}$ & $\mathbf{3}$ & $\mathbf{S D}$ & RSD & AVE \\
\hline $\mathbf{T}$ & 20.3 & 20.4 & 20.4 & 0.06 & 0.28 & 20.37 \\
\hline $\mathbf{p H}$ & 11.5 & 11.6 & 11.6 & 0.06 & 0.50 & 11.57 \\
\hline $\mathbf{E C}$ & 2105 & 2190 & 2230 & 63.84 & 2.93 & 2175.00 \\
\hline TDS & 1368.25 & 1423.5 & 1449.5 & 41.49 & 2.93 & 1413.75 \\
\hline NO3 & 67.4 & 67.8 & 69.3 & 1.00 & 1.47 & 68.17 \\
\hline Mg++ & 10.52 & 4.54 & 9.48 & 3.19 & 39.06 & 8.18 \\
\hline Ca++ & 171.356 & 190.572 & 190.572 & 11.09 & 6.02 & 184.17 \\
\hline HCO3 & 253.45 & 255.6 & 251.8 & 1.91 & 0.75 & 253.62 \\
\hline CO3 & 50.04 & 64.04 & 44.04 & 10.26 & 19.47 & 52.71 \\
\hline Cl & 196 & 164 & 156 & 21.17 & 12.31 & 172.00 \\
\hline Na & 443.6 & 436.1 & 443.6 & 4.33 & 0.98 & 441.10 \\
\hline K & 128.57 & 120 & 128.57 & 4.95 & 3.94 & 125.71 \\
\hline SO4 & 534.47 & 523.172 & 572.182 & 25.66 & 4.72 & 543.27 \\
\hline
\end{tabular}




\subsection{Result of sodium effect (Alkali Hazard) on soil properties and crop growth}

The importance of Sodium concentration in irrigation water comes in the next stage to concentrate total salts. Generally, sodium ions are present in higher concentrations than any ions of other elements, however, they are not more toxic than calcium ions or other elements. The standard for estimating the severity of sodium in water is to measure its percentage in the dissolved form, in addition to the remaining salts of sodium carbonate. Accordingly, the Ratio Adsorption-Sodium is calculated were shown in the following:

Table 5. Result of sodium effect (Alkali Hazard) on soil properties and crop growth

\begin{tabular}{|c|c|c|c|c|c|}
\hline Degree & SAR(meq/l) & $\mathbf{1}$ & $\mathbf{2}$ & $\mathbf{3}$ & $\mathbf{4}$ \\
\hline S1 & $0-----10$ & 2.65 & 7.84 & 1.88 & 4.164 \\
\hline S2 & $10----18$ & & & & \\
\hline S3 & $18-----26$ & & & & \\
\hline S4 & Larger than 26 & & & & \\
\hline
\end{tabular}

* S1 = It can be used on all lands without degradation.

* S2 = Its use has an effect on sensitive plants.

* S3 $=$ It use Espbtenco problems for most of the land and the need for special operations service when you use.

$*$ S4 $=$ It is not recommended for use.

\subsection{Result of Measuring the Total Amount of Dissolved Salts in the Water}

Measuring the total amount of dissolved salts in the water, and this is estimated by measuring the degree of electrical conductivity of the water electrical conductivity (EC) and the resulting reading with the micromose $(\mu$ mohs) is multiplied by a constant (65.0), and the result gives the concentration of the total dissolved salts as parts per million ppm.

Table 6. Result measuring of the total amount of dissolved salts in the water

\begin{tabular}{|c|c|c|c|c|c|}
\hline Degree & $\mathbf{E C}(\boldsymbol{\mu}$ mohs/cm) & $\mathbf{1}$ & $\mathbf{2}$ & $\mathbf{3}$ & $\mathbf{4}$ \\
\hline $\mathbf{C 1}$ & Less than 250 & & & & \\
\hline $\mathbf{C 2}$ & $250-750$ & & & & \\
\hline $\mathbf{C 3}$ & $750---2250$ & & 1600 & 1303 & 2175 \\
\hline $\mathbf{C 4}$ & Larger than 2250 & 12167 & & & \\
\hline
\end{tabular}

$* \mathrm{C} 1=$ Low risk $-* \mathrm{C} 2=$ Medium risk $-* \mathrm{C} 3=$ High risk $-* \mathrm{C} 4=$ Very high risk.

\subsection{Result of measuring the Residual Sodium Carbonate}

The Residual Sodium Carbonate (RSC) index of irrigation water or soil water is used to indicate the alkalinity hazard for soil. The RSC index is used to find the suitability of the water for irrigation in clay soils which have a 
high cation exchange capacity. When dissolved sodium in comparison with dissolved calcium and magnesium is high in water, clay soil swells or undergoes dispersion which drastically reduces its infiltration capacity.

In the dispersed soil structure, the plant roots are unable to spread deeper into the soil due to lack of moisture. However, high RSC index water does not enhance the osmotic pressure to impede the off take of water by the plant roots unlike high salinity water. Clay soils irrigation with high RSC index water leads to fallow alkali soils formation. RSC is expressed in meq/l units. RSC should not be higher than 1 and preferably less than +0.5 for considering the water use for irrigation. The formula for calculating RSC index is: $\mathrm{RSC}=\left(\mathrm{CO}_{3}+\mathrm{HCO}_{3}\right)-(\mathrm{Ca}+\mathrm{Mg})$.

Table 7. Result of measuring the Residual Sodium Carbonate

\begin{tabular}{|c|c|c|c|c|c|}
\hline Degree & RSC (meq/l) & $\mathbf{1}$ & $\mathbf{2}$ & $\mathbf{3}$ & $\mathbf{4}$ \\
\hline Water suitable for irrigation & Less than 1.25 & -40.94 & -13.50 & -42.22 & -10.40 \\
\hline Medium potency water for irrigation & $1.25--2.5$ & & & & \\
\hline Water not suitable for irrigation & Larger than 2.5 & & & & \\
\hline
\end{tabular}

3.10. Result of the effect of using irrigation with raw wastewater and treated wastewater on planting the selected seeds in the laboratory

After conducting the process of planting the selected seeds on Petri dishes and in the soil, and irrigation with raw wastewater and treated wastewater was monitored as following:

\subsubsection{Result of growing seeds in petri dishes}

The effect of irrigation on the growth of planting some seeds on Petri dishes with raw wastewater and treated wastewater as well as the rate of speed germination was monitored as follows:

\subsubsection{Result of growing seeds in petri dishes irrigation by raw wastewater}
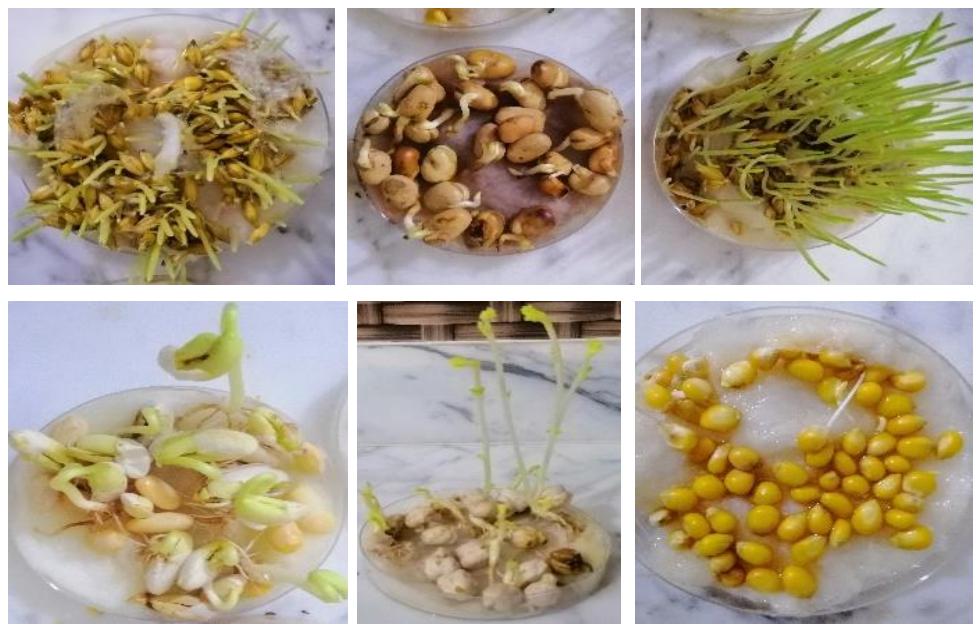

Fig.10. Result of growing seeds in petri dishes irrigation by raw wastewater

The cultivation of 6 kind seeds (Vicia faba, Cicer arietinun, Phaseolus vulgaris, Triticum aestivum, Hordeum vulgare and Zea mays) were done in Petri dishes and irrigation with raw wastewater and the effect of irrigation on 
the growth of the selected seeds was observed as a change in the size of the seeds and they became full and doubled in size and the appearance of the stem-like from each seed and the increase in length each day. The percentage of germination was about 80-90\% in most laboratory seeds and the germination speed was started in wheat and barley seeds after 2-4 days, followed by germination of other seeds (Vicia faba, Cicer arietinun, Phaseolus vulgaris and Zea mays) except that in this step a rot has been observed for some seeds and saw the appearance of some insects (Fig.10).

\subsubsection{Result of growing seeds in petri dishes irrigation by treated wastewater}

The cultivation of 6 kind seeds (Vicia faba, Cicer arietinun, Phaseolus vulgaris, Triticum aestivum, Hordeum vulgare and Zea mays) were done in Petri dishes and irrigated with treated wastewater and the effect of irrigation on the growth of the selected seeds was observed as change in the size of the seeds and became full and doubled in size and appearance of the stem-like from each seed also increase in length in each day. The rate of germination was about $80-90 \%$ in most laboratory seeds, germination speed was started in Triticum aestivum and Hordeum vulgare seeds after 3-4 days, followed by germination of other seeds (Vicia faba, Cicer arietinun, Phaseolus vulgaris and Zea mays) (Fig.11) .
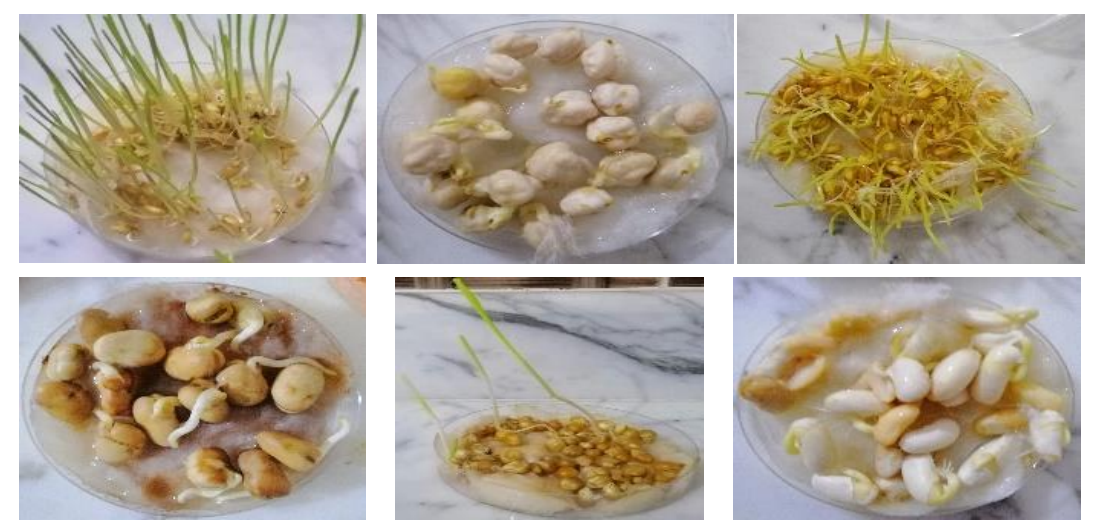

Fig.11. Result of growing seeds in petri dishes irrigation by treated wastewater

\subsection{Result of growing seeds in the soil}

The effect of irrigation on the growth of cultivation of 6 type of seeds (Vicia faba, Cicer arietinun, Phaseolus vulgaris, Triticum aestivum, Hordeum vulgare and Zea mays) on the soil and irrigation with raw and treated wastewater has been monitored in the following steps:

\subsubsection{Result of growing seeds in the soil irrigation by raw wastewater}
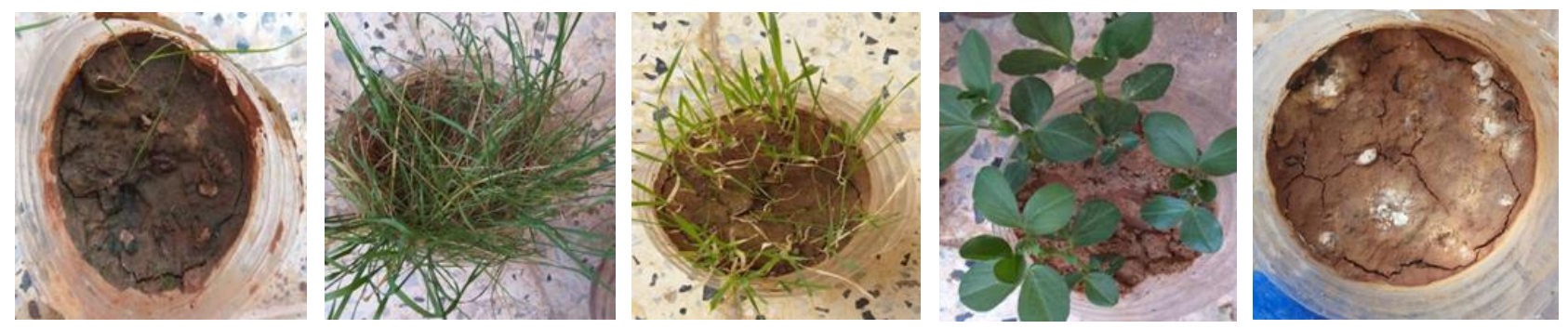

Fig.12. Result of growing seeds in the soil irrigation by raw wastewater 
The effect of irrigation on the growth of selected seeds showing the ability of speed germination in ponds containing clay soils, at the beginning saw the germination after 2-5 days in Triticum aestivum, Hordeum vulgare and Zea mays seeds firstly and then the germination of the seeds of the legume family within 4-7 days of planting (Fig.12). In addition, observed rot in the soil and yellowing leaves of some plants and some of seeds did not growth.

\subsubsection{Result of growing seeds in the soil irrigation by treated wastewater}

The effect of irrigation on the growth of the selected seeds was observed and showing the ability of seed germination in ponds containing clay soils, at the beginning of germination after 4-5 days in the seeds of Triticum aestivum, Hordeum vulgare and Zea mays firstly, and then seeds of the legume family (Vicia faba, Cicer arietinun and Phaseolus vulgaris) within 5-7 days of planting (Fig.13). Also, we have seen the speed of germination in plants irrigated by raw wastewater more faster than the plants irrigated by treated wastewater.
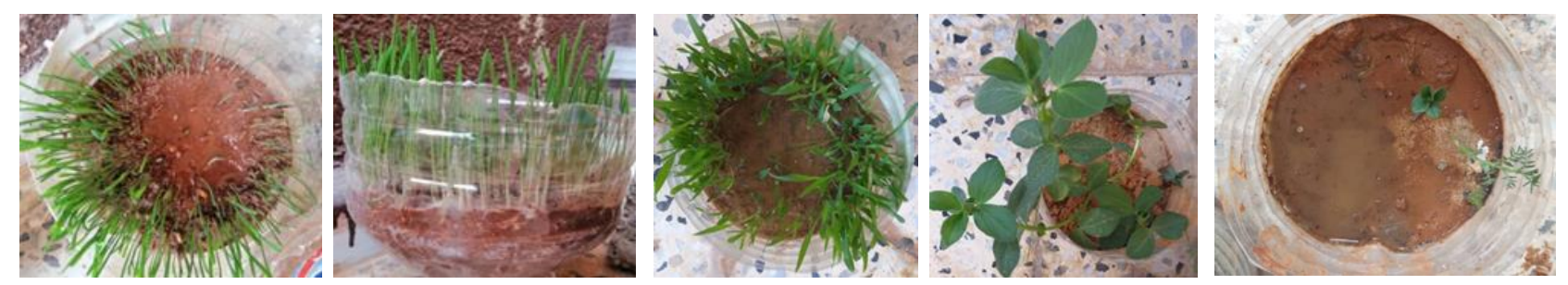

Fig.13. Result of growing seeds in the soil irrigation by treated wastewater

\section{Discussions}

Water has a precious value and each drop must be accounted for in water scare regions such as Middle East and North Africa. In this study which aimed and focused on the biological and chemical analysis techniques for wastewater sample collected from Alkiesh area in Benghazi city, Libya.

The results of invitro experiments of wastewater analysis showed positive data, which might be encourage use to reuse the treated wastewater in many nonhuman purposes. Water scarcity and water pollution or crucial issues in today's world. One of the ways to reduce the impact of water scarcity and pollution is to expand water and wastewater reuse. The increasing scarcity of water in the world along with rapid population in urban area give rise to concern about appropriate water management processes (Cavallini and young, 2002). The most significant evidence in this study is focus to study the microbial contamination specially pathogenic bacteria, the microscopic examination showed that only bacterial growth colony were Klebsiella pneumoniae, Pseudomonas aeruginosa and Escherichia coli in raw wastewater, while after treatment by use of economically efficient materials e.g., Charcoal and Lime (Calcium Carbonate) it were Escherichia coli and Pseudomonas aeruginosa respectively.

Therefore, wastewater has to be reclassified as a renewable water resource rather than waste as it helps increase water availability and at the same time prevents environmental pollution. This study discussed several options to achieve sustainability in wastewater treatment. The first was to carry out routinely monthly examination, biologically and chemically to make sure the wastewater is completely devoid from harmful microorganisms and toxic heavy metals. The second point by choosing an appropriate treatment method (Jimenez Cisneros, 2014). 
The current and of potential use of the treated wastewater for irrigation process is essential alternative for sustainable water management of wastewater is applied for aquaculture and artificial groundwater recharge. However, agriculture is the largest water consumer and the reuse of wastewater is extensively practiced for irrigation of cultivation soils. Agricultural irrigation is the oldest and most widespread reuse of the treated or untreated wastewater to grow food and energy crops (Scheierling et al., 2010).

The main risks and constraints for wastewater use in agriculture could include the presence of pathogens, possible pollution of the soil and of the aquifer. Universally, twenty million hectares of agricultural land is irrigated with direct use of untreated or treated wastewater (Bixio et al., 2008). The guidelines and laws regulating the wastewater reuse, several publications regarding the guideline and standards measurements for wastewater reuse were published worldwide. The World health organization published a series of guidelines about the safe use of wastewater in agriculture (WHO 1973, 1989, 2006). Similar to the WHO (2006), the EPA guidelines consider the water quality criteria for irrigation with emphasizing that the fine-textured neutral and alkaline soils have high capacities to remove the different pollutant elements. At the end of this brief discussion, more work and researches are needed nowadays with thought full concentration on wastewater management in Benghazi and in other Libyan cities.

\section{Conclusions}

As cities continue to grow and water resources continue to become more challenged, only water reuse, desalination, and transportation outside can provide additional resources than those provided by natural deposition. Water reuse in particular has numerous advantages, yet real challenges in terms of public acceptance. By conducting a treatment of wastewater samples with charcoal and lime, knowing the chemical and physical properties, conducting the detection of microorganisms before and after treatment, and using the treated water in agriculture, where the results were confirmed through some properties such as the analysis of Total Dissolved Salts (TDS) between 847-1414 mg1, Sodium Absorption Rate (SAR) between 1.88-7.8 meq/l, Electrical Conductivity (EC) between 1303 to 2175, Residual Sodium Carbonate (RSC) between - 42.22 to -10.40 and germination tests. It was found that it is possible to benefit from the treated wastewater to irrigate green areas and insensitive crops without soil degradation and according to the United States Salinity Laboratory. It cannot be used to irrigate sensitive crops, especially citrus fruits, and it should only be used in lands that do not have impervious layers that prevent leaching because they need washing.

Through the studies and analyzes that we have done in this research, we recommend the following: 1 . Rehabilitation or upgrading of existing wastewater treatment plants or the construction of new treatment plants. 2 . Providing support to the agricultural sector by the state and Education of the farmers to use treated wastewater in agriculture. 3. Establishment of proper standards for influent and effluent wastewater quality. 4. Environmental awareness and the population's understanding of the use of treated water. 5. Emphasizing the need to conduct routine microbiological analyzes to ensure the safety of treated wastewater in order to preserve human, animal and plant life. 6. We recommend the use of a mixture of charcoal and lime in treating wastewater, through the experiments we conducted, which proved that it is the most effective and efficient technology than other methods. 
Declarations

\section{Source of Funding}

This research did not receive any grant from funding agencies in the public, commercial, or not-for-profit sectors.

\section{Competing Interests Statement}

The authors declare no competing financial, professional and personal interests.

\section{Consent for publication}

Authors declare that they consented for the publication of this research work.

\section{Availability of data and material}

Authors are willing to share data and material according to the relevant needs.

\section{Acknowledgements}

The authors wish to express their sincere gratitude to Department of Botany, Faculty of Sciences, Benghazi University, Libya and Libyan Academy of Benghazi for providing necessary facilities to carry out this research.

\section{References}

[1] Al - Zu'bi, M. M., Jazdan, O., Majar, A., Groub, M. N., Darwish, H. and Haqoun, M. (2014). Use of treated wastewater in agriculture. ICBA. Agriculture for tomorrow.

[2] Bixio D., Theeye, C., Wintgens, T., Ravazzini, A., Miska, V., and Muston, M., (2008). Water reclamation and reuse: Implementation and management issues. Desalination. 218: 13-23.

[3] Cavallini \& Young, (2002). Integrated systems for the treatment and recycling of wastewater in Latin America. [4] Jimenez C. B., (2014). Water reuse and recycling. In Comprehensive Water Quality and Purification, Edited by Satinder Ahuja, Elsevier, Waltham, pp. 296-323.

[5] Kirby, (2016). Rainfall Patterns Cloud Climate Changes. Climate News Network. Retrieved from: http://clima tenewsnetwork.net/rainfall-patterns-cloud.

[6] Paranychianakis, N.V.; Salgot, M.; Snyder, S.A. and Angelakis, A.N., (2015). Quality Criteria for Recycled Wastewater Effluent in EU-Countries: Need for a Uniform Approach. Crit. Rev. Env. Sci. Tech. 45, pp.1409-1468. [7] Scheierling, S. M., Bartone, C., Mara D. D. and Drechsel (2010). Improving wastewater use in agriculture: An emerging priority, World Bank Policy Research working paper 5412, Washington, DC: World Bank. pp. 1-169.

[8] Terkawi, M. I. (2016). Stakeholders' Perspectives on Water Reuse in the Agricultural Sector in Lebanon. American University of Beirut. Master's project.

[9] Tsacev TS. (2001). Treatment of domestic waste water. Izdatelstvo Technika, Sofia.

[10] WHO, World Health Organization (1989). Health guidelines for the use of wastewater in agriculture and aquaculture. Technical report No.778, Geneva. pp. 1-74.

[11] WHO, World Health Organization (2001). Guidelines for the safe use of wastewater, excreta and greywater. [12] WHO, World Health Organization (1973). Reuse of effluents: Methods of wastewater treatment and health safeguards. Technical report No. 517, Geneva. pp. 1-63. 